University of Nebraska - Lincoln

DigitalCommons@University of Nebraska - Lincoln

U.S. Environmental Protection Agency Papers

U.S. Environmental Protection Agency

1997

\title{
The Agricultural Health Study: Factors Affecting Completion and Return of Self-Administered Questionnaires in a Large Prospective Cohort Study of Pesticide Applicators
}

\author{
Robert Tarone \\ National Cancer Institute \\ Michael Alavanja \\ National Cancer Institute \\ Sheila Hoar Zahm \\ National Cancer Institute \\ Jay Lubin \\ National Cancer Institute \\ Dale Sandler \\ National Institute of Environmental Health Sciences, \\ See next page for additional authors \\ Follow this and additional works at: https://digitalcommons.unl.edu/usepapapers \\ Part of the Civil and Environmental Engineering Commons
}

Tarone, Robert; Alavanja, Michael; Hoar Zahm, Sheila; Lubin, Jay; Sandler, Dale; McMaster, Suzanne; Rothman, Nathaniel; and Blair, Aaron, "The Agricultural Health Study: Factors Affecting Completion and Return of Self-Administered Questionnaires in a Large Prospective Cohort Study of Pesticide Applicators" (1997). U.S. Environmental Protection Agency Papers. 27.

https://digitalcommons.unl.edu/usepapapers/27

This Article is brought to you for free and open access by the U.S. Environmental Protection Agency at DigitalCommons@University of Nebraska - Lincoln. It has been accepted for inclusion in U.S. Environmental Protection Agency Papers by an authorized administrator of DigitalCommons@University of Nebraska - Lincoln. 


\section{Authors}

Robert Tarone, Michael Alavanja, Sheila Hoar Zahm, Jay Lubin, Dale Sandler, Suzanne McMaster, Nathaniel Rothman, and Aaron Blair 


\title{
The Agricultural Health Study: Factors Affecting Completion and Return of Self-Administered Questionnaires in a Large Prospective Cohort Study of Pesticide Applicators
}

\author{
Robert E. Tarone, PhD, ${ }^{1 *}$ Michael C.R. Alavanja, DrPh, ${ }^{1}$ Shelia Hoar Zahm, SCD, ${ }^{1}$ \\ J ay H. Lubin, PhD, ${ }^{1}$ Dale P. Sandler, PhD, ${ }^{2}$ Suzanne B. McMaster, PhD, ${ }^{3}$ \\ Nathaniel Rothman, MD, MHS, ${ }^{1}$ and Aaron Blair, PhD $^{1}$
}

\begin{abstract}
Response rates were examined in a prospective epidemiologic study of individuals, mostly farmers, from Iowa and North Carolina seeking a pesticide applicator license during the period from 1994 through 1996. In the first year of enrollment 16,535 farmers (representing 77\% of eligible farmer applicators) enrolled in the study by completing a 17-page questionnaire administered at a pesticide training session; $47 \%$ of the enrolled farmers completed and returned a much longer take-home questionnaire. The characteristics of farmers who completed only the enrollment questionnaire were quite similar to those of farmers who also completed and returned the take-home questionnaire. The most notable difference was the increased age of responders. Thus, the study population might have slightly higher cumulative farm exposures and slightly lower current farm exposures than the base population of all farmer applicators. The lack of evidence for substantial selection bias is reassuring for the Agricultural Health Study, and provides a measure of reassurance for other studies depending on the voluntary completion of self-administered questionnaires. Am. J. Ind. Med. 31:233-242, 1997. (1) 1997 Wiley-Liss, Inc.
\end{abstract}

KEY WORDS: epidemiologic methods; prospective cohort study; occupational exposure; selection bias (epidemiology); cancer

\section{INTRODUCTION}

Enrollment of subjects into a prospective epidemiologic study is often accomplished using a self-administered questionnaire. Questionnaires are usually mailed to eligible individuals, filled out at home, and returned by mail. In all

\footnotetext{
${ }^{1}$ Epidemiology and Biostatistics Program, National Cancer Institute, Bethesda, MD.

${ }^{2}$ National Institute of Environmental Health Sciences, Research Triangle Park, NC.

${ }^{3}$ Environmental Protection Agency, Research Triangle Park, NC.

*Correspondence to: Robert Tarone, National Cancer Institute, EPN 403, Bethesda, MD 20892.

Accepted for publication $1 \mathrm{~J}$ uly 1996.
}

(c) 1997 Wiley-Liss, Inc. TThis article is a US Government work and, as such, is in the public domain in the United States of America. epidemiologic studies, some eligible individuals refuse to participate, and such nonresponse can lead to selection bias [Wacholder et al., 1992]. Accordingly, there is considerable interest in identifying characteristics which distinguish responders from nonresponders in epidemiologic studies.

The Agricultural Health Study is a large prospective cohort study being conducted in Iowa and North Carolina to investigate potential adverse health effects of a variety of exposures related to farming [Alavanja et al., 1996]. The impetus for the study comes from experimental and epidemiological investigations which suggest that some agricultural exposures may contribute to excesses for certain cancers and other diseases [Blair and Zahm, 1991; Blair, 1992]. Study subjects are all licensed pesticide applicators, the majority of whom are farmers, and the spouses or domestic partners (hereafter simply spouses) of farmer 
applicators. Persons who apply restricted-use pesticides must undergo training or testing in the safe handling of pesticides at least every 3 years in order to obtain a pesticide applicator license. All individuals from Iowa and North Carolina seeking a pesticide application license from 1994 through 1996 will be invited to participate in the Agricultural Health Study.

Enrollment is accomplished by the completion of a self-administered questionnaire at a pesticide training or testing session. Each farmer applicator who completes an enrollment questionnaire is given a set of longer questionnaires (one to be completed by the farmer and two to be completed by the spouse) to be taken home, completed and returned by mail. During the first year of the 3-year enrollment period, 16,535 farmers, representing $77 \%$ of eligible farmer applicators, completed the enrollment questionnaire. Although this response rate for the enrollment questionnaire compares favorably with enrollment rates for other large prospective cohort studies [Doll and Hill, 1964; Barton et al., 1980; Chow et al., 1992; Potter et al., 1992; Boice et al., 1995], only $47 \%$ of the enrolled farmers returned the second, more burdensome, take-home questionnaire. In planning how to incorporate information from the second questionnaire into the statistical analysis of disease outcomes within the farmer cohort, it is important to determine the extent to which nonresponders differ from responders with regard to disease and exposure characteristics. In this paper, the responses from the enrollment questionnaire are compared between those farmers who returned and those who did not return the take-home questionnaire, in order to identify characteristics distinguishing individuals willing to complete at home and return a lengthy, self-administered questionnaire. Implications for the Agricultural Health Study and for other epidemiologic investigations will be elucidated.

\section{MATERIALS AND METHODS}

\section{Study Questionnaires}

In order to motivate eligible subjects to participate in the Agricultural Health Study, information on the study is presented during each pesticide training session. This information is presented by study staff in North Carolina and by agricultural extension agents in Iowa, but the presentation is, otherwise, the same in both states. Enrollment is achieved through return of a completed questionnaire at the end of a training session. The 17-page enrollment questionnaire seeks personal identifying information (i.e., name, birth date, Social Security number, and address) for the pesticide applicator, and if the applicator is married or living as married, for the spouse, in order to facilitate follow-up for future health outcomes. The enrollment questionnaire also requests sufficient information for a basic analysis of prospectively ascertained health outcomes. Thus, information is requested regarding applicator lifestyle and occupational factors, including smoking history, alcohol consumption, fruit and vegetable consumption, prior medical conditions, family history of disease, pesticide use, type of farm, and a variety of other farm-related activities.

The take-home, self-administered questionnaire seeks more detailed information on work practices, pesticide use, pesticide application procedures, health history, as well as information on other occupations and exposures, cooking practices, and additional lifestyle factors. In addition to providing information not ascertained through the enrollment questionnaire, the take-home questionnaire allows a more quantitative assessment of various agricultural exposures. Applicators who report being married or living as married are also given two questionnaires to be completed by their spouses and returned by mail. These questionnaires enroll the spouse in the study, verify identifying information provided by the applicator on the spouse, and seek information on spouse lifestyle and environmental exposures, including smoking history, alcohol consumption, cooking practices, direct and indirect agricultural exposures, personal medical history, and family history of disease.

\section{Investigation of Nonresponse}

The examination of predictors of nonresponse will be restricted to farmers in the Agricultural Health Study. Thus, the population investigated in this paper consists of all farmer applicators who enrolled in the study during the first year. The responses to questions on the enrollment questionnaire of the Iowa farmers and North Carolina farmers who returned the take-home questionnaire are compared to the corresponding responses of those farmers who did not return the take-home questionnaire. Due to the length of the enrollment questionnaire, the impact of factors not examined in previous studies of nonresponse (e.g., diet and alcohol use), in addition to a number of factors related to farming, can be investigated. Typically, either both applicator and spouse responded in a household, or neither responded, and thus this investigation will examine only the take-home questionnaire response rates for enrolled farmers.

Iowa and North Carolina differ substantially in both agricultural practices and in certain lifestyle characteristics, and there were minor differences in how the study was presented at the pesticide training sessions in the two states. Accordingly, the comparison of responders and nonresponders will be presented separately for each state. For each question on the enrollment questionnaire, the distributions of responses for farmers who returned the take-home questionnaire were compared to those for farmers who did not return the take-home questionnaire using the Pearson 
chi-square statistic. When the response to a question had a natural ordering (e.g., number of years of education or number of children) a chi-square trend statistic was employed. When adjustment for possible confounding was required, stratified chi-square analyses [Thomas and Gart, 1983] were performed, as indicated in the text or tables.

Because of the large number of questions examined, several significant differences between responders and nonresponders are expected to occur by chance alone. Approximately 160 comparisons were made in each state, but many of the responses were highly correlated (e.g., farmers often report a very similar spectrum of specific pesticides applied if they grow the same crops). In an attempt to adjust, but not overadjust, for multiple comparisons, a Bonferroni adjustment [Miller, 1981], assuming 100 comparisons was employed in each state, leading to a critical level of 0.0005 in determining the significance of differences by response status. All such significant findings are denoted in the tables. Conventionally significant (i.e., $\mathrm{p} \leq 0.05$ ) differences in one state which support significant findings by the more stringent criterion in the other state, are reported in the text.

\section{RESULTS}

In the first year of the Agricultural Health Study, 8,764 Iowa farmers and 7,771 North Carolina farmers enrolled in the study. Of these enrollees, 4,492 (51.3\%) Iowa farmers and 3,362 (43.3\%) North Carolina farmers returned the take-home questionnaire. Among farmers who were married or living as married, the response rates for the return of the spouse questionnaire in Iowa and North Carolina were $51.4 \%$ and $43.6 \%$, respectively.

Table I compares responders and nonresponders by their ages at enrollment. In both Iowa and North Carolina the responders were significantly older than the nonresponders. The age difference was substantial; the average age at enrollment was 48.3 for Iowa responders, 44.0 for Iowa nonresponders, 50.7 for North Carolina responders, and 46.1 for North Carolina nonresponders. Because responses to many questions in the enrollment questionnaire are likely to depend on age, all subsequent comparisons of responders and nonresponders will be age-adjusted using stratified chi-square analyses, with year of birth stratified as follows: prior to 1926, 1926-1935, 1936-1945, 1946-1955, 19561965, and after 1965. Similarly, subsequent frequency distributions will be directly age-standardized to the age distribution of all enrolled study subjects in both states.

Distributions of farmers by month of enrollment in the study (data not shown) differed significantly between responders and nonresponders in each state, with responders more likely to have enrolled during winter months. The age-adjusted percentages of responders who enrolled from November to February were $84.1 \%$ in Iowa and $64.8 \%$ in North Carolina; the comparable percentages for nonre-
TABLE I. Age at Enrollment Distribution (Percentage) for Farmers Enrolled into the Agricultural Health Study

\begin{tabular}{crrrrr} 
& \multicolumn{2}{c}{ lowa } & & \multicolumn{2}{c}{ North Carolina } \\
\cline { 2 - 3 } \cline { 5 - 6 } Years & $\mathbf{Q}^{\text {a }}$ & No Q & & Q & No Q \\
\hline 528 & 6.3 & 9.7 & 6.7 & 11.4 \\
$29-38$ & 20.5 & 28.8 & 16.0 & 22.9 \\
$39-48$ & 26.2 & 29.1 & 23.2 & 24.6 \\
$49-58$ & 23.4 & 19.4 & 23.2 & 21.0 \\
$59-68$ & 18.2 & 10.6 & 20.0 & 13.8 \\
$\geq 69$ & 5.4 & $2.5^{b}$ & 10.9 & $6.4^{b}$ \\
\hline
\end{tabular}

aQ: Enrolled farmers who completed and returned the take-home questionnaire; $\mathrm{N}=4,492$ in lowa and N = 3,362 in North Carolina. No Q: Enrolled farmers who failed to complete and return the take-home questionnaire; $N=4,272$ in lowa and $N=4,409$ in North Carolina. bSignificant difference between distribution for responders and nonresponders, with $p<$ 0.0005 .

sponders were $77.4 \%$ and $57.7 \%$ in Iowa and North Carolina, respectively. Viewed in a different way, the ageadjusted response rates for farmers enrolling in November through February were $52.1 \%$ in Iowa and $52.9 \%$ in North Carolina, while for farmers enrolled in all other months the response rates were $41.1 \%$ in Iowa and $45.4 \%$ in North Carolina. Thus, the higher crude response rate for return of the take-home questionnaire in Iowa (i.e., $51.3 \%$ in Iowa, compared to $43.3 \%$ in North Carolina) is due to the fact that a significantly higher percentage of farmers in Iowa attended testing or training sessions held during winter months, when there were fewer farm responsibilities.

Educational differences were not large (Table II); the percentages of subjects with education beyond high school were $45.3 \%$ for responders and $41.8 \%$ for nonresponders in Iowa, and $42.2 \%$ for responders and $37.1 \%$ for nonresponders in North Carolina. Nonetheless, responders were more educated in both states ( $p=0.002$ in Iowa). Marital status distributions for responders and nonresponders showed no substantial discordance (Table II), but differed significantly in Iowa, with responders being more likely than nonresponders to have never married and slightly less likely to be divorced. Responders in North Carolina also differed somewhat from nonresponders by marital status ( $p=$ 0.0013), with responders again being slightly more likely to have never married. For farmers who reported having ever been married there was a tendency for nonresponders to have larger families in both states ( $p=0.044$ in Iowa). The percentages of married farmers with 3 or more children were $50.5 \%$ for responders and $52.9 \%$ for nonresponders in Iowa, and $30.7 \%$ for responders and $33.4 \%$ for nonresponders in North Carolina. Responders tended to be less likely to have had a recent birth, but the difference was not significant in either state. 
TABLE II. Distributiona (Percentage) of Highest Educational Level Achieved, Marital Status, Number of Children, and the Birth of a Baby Within the Past 9 Years for Farmers Enrolled in the Agricultural Health Study

\begin{tabular}{|c|c|c|c|}
\hline \multicolumn{2}{|c|}{ lowa } & \multicolumn{2}{|c|}{ North Carolina } \\
\hline $\mathbf{Q}^{\mathrm{b}}$ & No $Q^{b}$ & $\mathbf{Q}$ & No Q \\
\hline
\end{tabular}

\begin{tabular}{|c|c|c|c|c|}
\hline \multicolumn{5}{|c|}{ Highest Level of Education } \\
\hline $1-8$ years & 3.4 & 3.0 & 6.2 & 6.8 \\
\hline Some HS & 2.3 & 3.3 & 9.0 & 12.3 \\
\hline HS grad & 49.0 & 52.0 & 42.7 & 43.8 \\
\hline Beyond HS & 27.1 & 25.8 & 20.9 & 19.7 \\
\hline College grad & 15.6 & 13.8 & 16.4 & 13.7 \\
\hline Beyond College & 2.6 & 2.2 & 4.9 & $3.7^{c}$ \\
\hline \multicolumn{5}{|c|}{ Marital Status } \\
\hline Never married & 12.5 & 9.9 & 12.8 & 10.2 \\
\hline Married & 84.4 & 85.4 & 79.6 & 82.5 \\
\hline Divorced & 2.6 & 3.9 & 6.0 & 5.6 \\
\hline Widowed & 0.5 & $0.8^{c}$ & 1.6 & 1.6 \\
\hline \multicolumn{5}{|c|}{ Number of Children ${ }^{d}$} \\
\hline 0 & 9.8 & 8.1 & 13.4 & 11.6 \\
\hline 1 & 8.4 & 9.6 & 19.2 & 17.7 \\
\hline 2 & 31.4 & 29.3 & 36.7 & 37.3 \\
\hline 3 & 27.4 & 28.6 & 18.9 & 19.2 \\
\hline $4-5$ & 18.4 & 20.1 & 9.8 & 12.0 \\
\hline$\geq 6$ & 4.7 & 4.2 & 2.0 & $2.2^{c}$ \\
\hline \multicolumn{5}{|c|}{ Baby in Last 9 Years ${ }^{d}$} \\
\hline Yes & 27.2 & 29.1 & 23.1 & 23.6 \\
\hline
\end{tabular}

aRelative frequency distributions age-adjusted by direct standardization to the combined study population in both states.

${ }^{b} Q$, No Q, see Table I.

cSignificant difference between distribution for responders and nonresponders in agestratified analysis, $p<0.0005$.

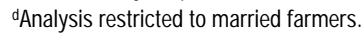

Table III compares tobacco and alcohol use by response status. Although similar percentages of responders and nonresponders reported ever smoking cigarettes, responders were more likely than nonresponders to have quit smoking cigarettes $(p=0.005$ in Iowa). There were no significant differences between responders and nonresponders in the numbers of cigarettes smoked per day during smoking years, and, although not shown in the table, in the duration of smoking cigarettes or in the use of tobacco products other than cigarettes. Nonresponders consumed alcohol slightly more often than responders ( $\mathrm{p}=0.05$ in North Carolina); $22.2 \%$ of Iowa responders, $25.3 \%$ of Iowa nonresponders, $13.2 \%$ of North Carolina responders, and $15.2 \%$ of North Carolina nonresponders consumed alcohol 2 or more times a
TABLE III. Distributiona (Percentage) of Tobacco and Alcohol Use for Farmers Enrolled in the Agricultural Health Study

\begin{tabular}{|c|c|c|c|c|}
\hline & \multicolumn{2}{|c|}{ lowa } & \multicolumn{2}{|c|}{ North Carolina } \\
\hline & $\mathbf{Q}^{\mathrm{b}}$ & No $Q^{b}$ & $\mathbf{Q}$ & No $Q$ \\
\hline \multicolumn{5}{|c|}{ Cigarette Smoking } \\
\hline Ever smoke & 38.9 & 39.9 & 57.5 & 59.5 \\
\hline Quit smoking & 72.1 & 66.7 & 60.8 & $53.9 c$ \\
\hline \multicolumn{5}{|c|}{ Number of Cigarettes Per Year } \\
\hline$\leq 10$ & 32.6 & 31.0 & 24.7 & 22.6 \\
\hline $11-20$ & 38.5 & 40.5 & 39.7 & 41.2 \\
\hline $21-40$ & 24.5 & 24.8 & 30.0 & 30.2 \\
\hline$>40$ & 4.4 & 3.7 & 5.7 & 6.0 \\
\hline \multicolumn{5}{|c|}{ Frequency of Alcohol Consumption } \\
\hline Never & 23.8 & 22.8 & 52.6 & 50.8 \\
\hline$<1$ per mo & 20.5 & 18.3 & 16.3 & 16.1 \\
\hline 1-3 per mo & 20.5 & 18.6 & 10.7 & 10.2 \\
\hline 1 day/wk & 13.0 & 14.9 & 7.1 & 7.7 \\
\hline 2-4 days/wk & 15.9 & 18.2 & 8.7 & 10.3 \\
\hline$\geq 5$ days/wk & 6.3 & $7.1^{\mathrm{c}}$ & 4.5 & 4.9 \\
\hline
\end{tabular}

aAg-adjusted relative frequency distributions, see Table II.

${ }^{\circ} \mathrm{Q}$, No Q, see Table I.

‘Significant difference, see Table II.

week. Nonresponders consumed slightly more alcohol on those occasions when they drank, but the differences were not statistically significant in either state (data not shown).

Table IV presents the distributions for frequency of vegetable and fruit consumption among enrolled farmers. Responders consumed vegetables significantly more often than nonresponders in both states; the percentage of individuals consuming vegetables at least once a day was $48.0 \%$ for responders compared to $42.8 \%$ for nonresponders in Iowa, and $53.3 \%$ for responders compared to $48.5 \%$ for nonresponders in North Carolina. Responders also ate fruit more often than nonresponders ( $\mathrm{p}=0.024$ for North Carolina), but the disparity between responders and nonresponders in fruit consumption was smaller than that for vegetable consumption.

There was no evidence of any differences between responders and nonresponders in the types of crops or livestock produced in either state (data not shown). The numbers of acres planted in crops and the numbers of livestock tended in the past year are compared in Table V. There were inverse relationships in both states between age and the number of acres planted and the number of livestock tended (data not shown). After age-adjustment there remained a slight tendency for nonresponders to be involved in larger farming enterprises than responders, although the 
TABLE IV. Distributiona (Percentage) of Frequency of Vegetable and Fruit Consumption for Farmers Enrolled in Agricultural Health Study

\begin{tabular}{|c|c|c|c|c|}
\hline & \multicolumn{2}{|c|}{ lowa } & \multicolumn{2}{|c|}{ North Carolina } \\
\hline & $\mathbf{Q}^{\mathrm{b}}$ & No $Q^{b}$ & $\mathbf{Q}$ & No $Q$ \\
\hline \multicolumn{5}{|c|}{ Vegetable Consumption } \\
\hline$\leq 2$ per wk & 10.7 & 12.3 & 10.0 & 14.1 \\
\hline 3-4 per wk & 21.9 & 25.1 & 19.5 & 20.2 \\
\hline 5- 6 per wk & 19.6 & 19.9 & 17.1 & 17.1 \\
\hline 1 per day & 19.7 & 17.7 & 11.0 & 10.0 \\
\hline 1.5 per day & 11.0 & 9.3 & 6.5 & 5.9 \\
\hline 2 per day & 14.1 & 12.6 & 22.0 & 20.8 \\
\hline$\geq 3$ per day & 3.2 & $3.2^{c}$ & 13.8 & $11.8^{\circ}$ \\
\hline \multicolumn{5}{|c|}{ Fruit Consumption } \\
\hline$<1$ per wk & 7.1 & 7.8 & 10.2 & 11.0 \\
\hline 1-2 per wk & 19.1 & 21.6 & 28.4 & 29.8 \\
\hline 3-4 per wk & 27.8 & 28.7 & 26.6 & 26.2 \\
\hline 5- 6 per wk & 15.3 & 14.2 & 11.3 & 11.3 \\
\hline 1-1.5 per day & 21.5 & 20.3 & 15.5 & 14.9 \\
\hline$\geq 2$ per day & 9.2 & $7.4^{c}$ & 8.1 & 6.8 \\
\hline
\end{tabular}

aAge-adjusted relative frequency distributions, see Table II. 'Q, No Q, see Table I.

cSignificant difference, see Table II.

distributions did not differ significantly by response status in either state by the stringent rejection criterion (although in Iowa, $\mathrm{p}=0.042$ for acres planted and $\mathrm{p}=0.014$ for number of livestock). There were no significant differences between nonrespondents and respondents in the number of years involved in pesticide mixing and application after age adjustment, but there were differences in the number of days spent in the past year in pesticide mixing and application $(\mathrm{p}=0.039$ in Iowa), with responders spending fewer days mixing and applying pesticides than nonresponders in both states.

Table VI examines the types of pesticides applied personally by farmers in the past year, both by general class of pesticide, and by individually specified pesticides. Herbicide application was the most common type of pesticide application in both states, and responders were more likely than nonresponders to have applied herbicides in both states ( $p=0.001$ for North Carolina). Iowa responders were also more likely to have applied a number of specific herbicides, while responders in both states were more likely to have applied the herbicide glyphosate. The results for ever having applied specific pesticides (data not shown) were similar to the results for application in the past year, with responders having applied a number of different herbicides significantly more often in Iowa, and glyphosate significantly more often in both states. Responders were somewhat more likely to
TABLE V. Distribution (Percentage) of Number of Acres Planted in Crops and Number of Livestock Tended and Duration and Frequency of Personal Pesticide Application for Farmers Enrolled in the Agricultural Health Study

\begin{tabular}{|c|c|c|c|}
\hline \multicolumn{2}{|c|}{ lowa } & \multicolumn{2}{|c|}{ North Carolina } \\
\hline $\mathbf{Q}^{b}$ & No $Q^{b}$ & $\mathbf{Q}$ & No $Q$ \\
\hline \multicolumn{4}{|c|}{ ber of Acres Planted in Past 12 Months } \\
\hline 0.4 & 0.4 & 3.9 & 4.5 \\
\hline 0.2 & 0.3 & 13.8 & 11.6 \\
\hline 1.9 & 1.9 & 27.6 & 24.2 \\
\hline 15.6 & 13.6 & 21.3 & 22.0 \\
\hline 36.0 & 35.0 & 15.4 & 17.0 \\
\hline 29.5 & 31.0 & 8.9 & 11.0 \\
\hline 16.3 & 17.9 & 9.2 & 9.8 \\
\hline
\end{tabular}

Number of Livestock Tended in Past 12 Months

$\begin{array}{lrrrr}\text { None } & 22.8 & 20.5 & 51.3 & 51.2 \\ <50 & 8.2 & 8.4 & 27.5 & 25.6 \\ 50-99 & 7.3 & 8.9 & 9.1 & 8.6 \\ 100-499 & 26.5 & 24.5 & 8.0 & 9.1 \\ 500-999 & 17.7 & 17.2 & 0.9 & 1.9 \\ \geq 1,000 & 17.5 & 20.5 & 3.1 & 3.7 \\ & & & \\ & \text { Pesticide Mixing and Application: Duration } & \\ \leq 1 \mathrm{yr} & & & & \\ 2-5 \mathrm{yr} & 1.9 & 2.1 & 3.1 & 3.8 \\ 6-10 \mathrm{yr} & 11.5 & 12.1 & 13.2 & 14.2 \\ 11-20 \mathrm{yr} & 13.9 & 15.8 & 19.7 & 18.4 \\ 21-30 \mathrm{yr} & 35.1 & 33.7 & 32.7 & 32.3 \\ >30 \mathrm{yr} & 23.7 & 24.1 & 18.7 & 19.3 \\ & 13.9 & 12.2 & 12.6 & 12.0 \\ & & & & \\ <5 \text { days/yr } & 15.6 & 15.2 & 20.6 & 18.4 \\ 5-9 \text { days/yr } & 27.6 & 26.1 & 19.1 & 17.0 \\ 10-19 \text { days/yr } & 34.2 & 33.7 & 22.9 & 23.9 \\ 20-39 \text { days/yr } & 17.6 & 20.0 & 23.2 & 23.4 \\ 40-59 \text { days/yr } & 3.4 & 3.0 & 6.9 & 8.5 \\ \geq 60 \text { days/yr } & 1.6 & 2.1 & 7.4 & 8.7 c \\ & & & & \end{array}$

aAge-adjusted relative frequency distributions, see Table II.

'QQ, No Q, see Table I.

cSignificant difference, see Table II.

have ever applied insecticides which had been on the market for a longer period of time, such as lindane, malathion, and carbaryl, as well as insecticides which were no longer on the market, such as chlordane and heptachlor. Small differences in ever having applied 2,4,5-T and DDT were not significant.

Methods used to apply pesticides are compared in Table VII. Although responders and nonresponders were generally 
TABLE VI. Distributiona (Percentage) of Pesticides Applied in the Past Year by Farmers Enrolled in the Agricultural Health Study

\begin{tabular}{|c|c|c|c|c|}
\hline & \multicolumn{2}{|c|}{ lowa } & \multicolumn{2}{|c|}{ North Carolina } \\
\hline & $\mathbf{Q}^{b}$ & No $Q^{b}$ & $\mathbf{Q}$ & No Q \\
\hline \multicolumn{5}{|c|}{ General Class of Pesticide } \\
\hline Herbicide & 84.0 & $79.2^{c}$ & 69.5 & 65.6 \\
\hline Insecticided & 55.6 & 55.6 & 61.9 & 60.7 \\
\hline Insecticide ${ }^{e}$ & 33.8 & 32.8 & 17.3 & 16.7 \\
\hline Fungicide & 2.2 & 2.3 & 31.5 & 28.8 \\
\hline Fumigant & 1.2 & 1.6 & 21.4 & 19.1 \\
\hline \multicolumn{5}{|c|}{ Herbicides } \\
\hline Alachlor & 13.3 & $9.8^{c}$ & 8.4 & 8.2 \\
\hline Atrazine & 32.8 & $28.3^{c}$ & 16.2 & 15.3 \\
\hline $2,4-D$ & 39.5 & $33.7^{c}$ & 17.5 & 16.4 \\
\hline Dicamba & 23.3 & $19.3^{c}$ & 5.0 & 4.7 \\
\hline Glyphosate & 37.9 & $31.7^{c}$ & 38.9 & $32.0^{c}$ \\
\hline Imazethapyr & 34.9 & $29.6^{c}$ & 3.3 & 3.0 \\
\hline Metolachlor & 22.5 & 19.8 & 11.0 & 9.8 \\
\hline Trifluralin & 20.5 & 18.5 & 6.1 & 6.3 \\
\hline \multicolumn{5}{|c|}{ Insecticides, Fungicides, and Fumigants } \\
\hline Permethrin ${ }^{d}$ & 2.1 & 2.1 & 7.0 & 5.7 \\
\hline Terbufos & 13.9 & 13.8 & 7.6 & 7.5 \\
\hline Fonofos & 5.0 & 5.5 & 1.6 & 1.6 \\
\hline Chlorpyrifos & 15.9 & 13.2 & 14.6 & 14.8 \\
\hline Coumaphos & 2.8 & 2.1 & 3.5 & 2.7 \\
\hline Permethrine & 5.9 & 4.9 & 1.3 & 1.6 \\
\hline Captan & 3.6 & 2.7 & 5.1 & 3.4 \\
\hline Brom-0-Gas & 0.1 & 0.2 & 13.4 & 11.5 \\
\hline Chlorothalonil & 0.4 & 0.3 & 9.4 & 8.4 \\
\hline
\end{tabular}

aAge-adjusted relative frequency distributions, see Table II.

${ }^{\mathrm{b} Q}$, No Q, see Table I.

cSignificant difference, see Table II.

${ }^{\mathrm{d} A p p l i e d}$ to crops.

eApplied to animals or poultry.

similar in pesticide application methods, responders in both states were significantly more likely to use hand sprayers or backpack sprayers. The greater use of hand spraying devices by responders persisted after stratified analyses adjusting for the numbers of acres planted or the number of days per year spent mixing and applying pesticides. Responders in Iowa were more likely to use boom sprayers pulled by a tractor, but there was no evidence of such a difference in North Carolina. As shown in Table VIII, responders were slightly more likely to report use of protective equipment while mixing and applying pesticides, although the difference was significant only for chemical resistant glove use in Iowa. There were no significant differences in reported symptoms after pesticide mixing and application in either state.
TABLE VII. Distributiona (Percentage) of Methods Used to Apply Pesticides for Farmers Enrolled in the Agricultural Health Study

\begin{tabular}{lrrrrr} 
& \multicolumn{2}{c}{ lowa } & & \multicolumn{2}{c}{ North Carolina } \\
\cline { 2 - 3 } \cline { 5 - 6 } & $\mathbf{Q}^{\mathrm{b}}$ & No Q & & $\mathbf{Q}$ & No Q \\
\hline Boom tractor & 77.1 & $71.7^{\mathrm{c}}$ & & 67.0 & 67.8 \\
Hand spray & 69.7 & $61.3^{\mathrm{c}}$ & & 56.8 & $49.2^{\mathrm{c}}$ \\
Backpack & 20.1 & $16.5^{\mathrm{c}}$ & & 39.7 & $34.2^{\mathrm{c}}$ \\
Gas canister & 1.9 & 1.5 & & 14.7 & 12.8 \\
Row fumigate & 0.7 & 0.6 & & 15.0 & 14.9 \\
Furrow/banded & 61.7 & 58.7 & & 29.1 & 26.0 \\
Seed treated & 27.6 & 25.3 & & 22.5 & 20.0 \\
Powder duster & 9.6 & 8.3 & & 21.3 & 18.9 \\
Mist blower & 6.2 & 6.3 & & 6.7 & 6.9 \\
Inject animal & 35.5 & 33.5 & & 15.7 & 14.9 \\
Dip animal & 13.9 & 14.7 & & 13.3 & 13.7 \\
Spray animal & 51.1 & 47.3 & 22.1 & 21.0 \\
Ear tags & 25.5 & 27.0 & 11.3 & 11.4 \\
Dust animal & 33.5 & 32.0 & 26.4 & 22.5 \\
\hline
\end{tabular}

aAge-adjusted relative frequency distributions, see Table II.

${ }^{b} \mathrm{Q}$, No Q, see Table I.

cSignificant difference, see Table Il.

Table IX summarizes the participation of farmers in a variety of work tasks. Responders were somewhat more likely to have repaired pesticide application equipment $(\mathrm{p}=$ 0.005 in North Carolina) and to have been involved in painting $(\mathrm{p}=0.001$ in Iowa). Nonresponders were slightly more likely than responders to have butchered animals. In general, however, responders and nonresponders differed little in the types of tasks performed.

Table X compares the distributions of previous disease and history of disease in at least one first degree relative. Responders did not report significantly more prior diagnoses of disease than nonresponders, although there was a slight increase in the percentage of responders reporting a prior diagnosis of cancer. A higher percentage of responders reported a diagnosis of any cancer in a first degree relative in both states ( $p=0.002$ for Iowa); however, differences in reported family history of specific malignancies were negligible. There was no evidence in either state of any increase by responders in the reporting of lymphopoietic malignancies in themselves or their relatives.

\section{DISCUSSION}

The enrollment rate of $77 \%$ for the Agricultural Health Study compares favorably with enrollment rates in previous large, prospective studies in which enrollment was accomplished through a self-administered questionnaire. The British Doctors Study [Doll and Hill, 1964] enrolled 69\% of the men and $60 \%$ of the women initially approached, the 
TABLE VIII. Distribition ${ }^{\mathrm{a}}$ of Use of Pesticide Protective Equipment and Reported Symptoms After Pesticide Mixing and Application for Farmers Enrolled in the Agricultural Health Study

\begin{tabular}{|c|c|c|c|c|}
\hline & \multicolumn{2}{|c|}{ lowa } & \multicolumn{2}{|c|}{ North Carolina } \\
\hline & $Q^{b}$ & No $Q^{b}$ & $\mathbf{Q}$ & No $Q$ \\
\hline \multicolumn{5}{|c|}{ Pesticide Protective Equipment Used } \\
\hline Work gloves & 12.6 & 14.1 & 23.1 & 21.9 \\
\hline Chem gloves & 83.1 & $77.1^{d}$ & 43.4 & 40.4 \\
\hline Face shield & 51.3 & 47.7 & 36.7 & 33.7 \\
\hline Gas mask & 9.8 & 8.1 & 19.8 & 19.3 \\
\hline Dispe clothes & 9.4 & 8.7 & 9.7 & 9.1 \\
\hline \multicolumn{5}{|c|}{ Symptoms After Pesticide Mixing and Application } \\
\hline Tired & 16.0 & 14.9 & 14.5 & 14.8 \\
\hline Headaches & 30.6 & 28.7 & 25.7 & 26.2 \\
\hline Nausea & 6.3 & 6.0 & 6.8 & 8.5 \\
\hline Skin Irrf & 23.5 & 21.6 & 19.4 & 18.3 \\
\hline Eye $I r^{f}$ & 17.0 & 16.4 & 21.3 & 20.0 \\
\hline Chest pain & 8.6 & 7.6 & 8.9 & 8.7 \\
\hline Nervous & 11.8 & 11.5 & 10.9 & 12.0 \\
\hline See doctor & 7.8 & 6.4 & 7.4 & 7.1 \\
\hline Hospitalized & 0.7 & 0.6 & 1.8 & 1.6 \\
\hline
\end{tabular}

age-adjusted relative frequency distributions, see Table II.

${ }^{\mathrm{b}} \mathrm{Q}$, No Q, see Table I.

'Chemical resistant.

dSignificant difference, see Table Il.

eDisposable.

flrritation.

Nurses' Health Study [Barton et al., 1980] achieved a 71\% response rate, the Lutheran Brotherhood Study [Chow et al., 1992] enrolled $68 \%$ of targeted men, and the Radiologic Technologist Study [Boice et al., 1995] had an enrollment rate based only on the self-administered questionnaire of 68\%. The Iowa Women's Health Study [Potter et al., 1992] enrolled only $43 \%$ of women, aged 55-69 years, randomly selected from licensed drivers in Iowa. Early investigations regarding survey questionnaire response indicated that higher response rates could be achieved in a homogeneous population with a shared interest in the research topic [Suchman, 1940; Edgerton et al., 1943; Wallace, 1947]. The lower response rate in the Iowa Women's Health Study may partially be explained by the more heterogeneous study population without an obvious shared health concern. The higher enrollment rate for the Agricultural Health Study is noteworthy, because it was achieved using the longest enrollment questionnaire of the above-mentioned studies. This may reflect the homogeneous study population with shared interest in factors affecting the health of farm families. The high enrollment rate, however, is likely due in large part to the fact that the self-administered enrollment
TABLE IX. Distributiona of Farm Tasks Performed by Enrolled Farmers in the Agricultural Health Study

\begin{tabular}{lccccc} 
& \multicolumn{2}{c}{ lowa } & & \multicolumn{2}{c}{ North Carolina } \\
\cline { 2 - 3 } \cline { 5 - 6 } & $\mathbf{Q}^{\mathrm{b}}$ & No Q & & $\mathbf{Q}$ & No Q \\
\hline Engine repair & 42.4 & 43.6 & & 41.9 & 41.6 \\
Pestc repair & 68.5 & $60.7^{\mathrm{d}}$ & & 57.2 & 53.2 \\
Butcher animal & 11.0 & 12.3 & & 12.6 & $15.8^{\mathrm{d}}$ \\
Vete services & 65.5 & 65.4 & & 27.8 & 27.0 \\
Brake lining & 13.4 & 13.8 & & 20.5 & 20.6 \\
Handle grain & 87.6 & 86.9 & 34.9 & 35.8 \\
Handle hay & 65.8 & 65.1 & 42.2 & 38.7 \\
Grind feed & 60.8 & 60.1 & & 17.4 & 19.4 \\
Handle silage & 25.6 & 27.0 & 7.3 & 7.3 \\
Weld & 78.9 & 76.5 & 47.9 & 46.1 \\
Paint & 75.0 & 71.7 & 54.6 & $49.6^{\mathrm{d}}$ \\
Tend swine & 41.4 & 40.8 & 7.2 & 8.6 \\
\hline
\end{tabular}

aAge-adjusted relative frequency distributions, see Table II.

${ }^{\mathrm{b}} \mathrm{Q}$, No Q, see Table I.

cPresticide application equipment.

dSignificant difference, see Table II.

eVeterinary.

questionnaire is filled out at a pesticide safety training session rather than at home.

No information is available regarding the $23 \%$ of eligible farmers who declined to fill out the enrollment questionnaire, but the experience in the Agricultural Health Study with regard to return rates for the take-home questionnaire can, nonetheless, provide useful information for current and future prospective studies. In particular, the comparison of return rates for subjects who did, or did not, complete the lengthy take-home questionnaire provides a means of assessing the extent to which participants in studies based on self-administered questionnaires may represent a biased sample with regard to exposure or disease history. This is less of a concern for outcomes ascertained through follow-up subsequent to the completion of the questionnaire (e.g., deaths or cancers identified in future years by record linkage) than for outcomes ascertained via the questionnaire (e.g., some neurologic symptoms and reproductive outcomes surveyed in the Agricultural Health Study).

Overall, the responses on the enrollment questionnaire of farmers who completed and returned the take-home questionnaire were remarkably similar to the responses on the enrollment questionnaire of farmers who did not return the take-home questionnaire. Even when there were significant differences between responders and nonresponders, the magnitude of the differences were, in general, not substantial, usually differing by only a few percent. In particular, differences with regard to important, known risk factors for cancer, such as ever smoking cigarettes, use of snuff or 
TABLE X. Distributiona of Disease Diagnoses and Family History of Disease for Farmers Enrolled in the Agricultural Health Study

\begin{tabular}{lllll}
$\frac{2}{\text { lowa }}$ & & \multicolumn{2}{c}{ North Carolina } \\
${ } }$ & No $Q^{b}$ & & $Q \quad$ No $Q$
\end{tabular}

Previously Diagnosed in Farmers

\begin{tabular}{|c|c|c|c|c|}
\hline Asthma & 6.5 & 5.8 & 6.6 & 6.1 \\
\hline Pneumonia & 17.4 & 16.1 & 15.5 & 14.5 \\
\hline Melanoma & 4.4 & 3.3 & 4.3 & 4.2 \\
\hline Skin cancerc & 4.8 & 4.8 & 7.7 & 6.8 \\
\hline Hodgkin's Disease & 0.7 & 1.1 & 0.8 & 0.7 \\
\hline Non-Hodgkin's lymphoma & 0.9 & 1.1 & 0.9 & 0.7 \\
\hline Leukemia & 0.7 & 1.0 & 0.7 & 0.8 \\
\hline Any cancer ${ }^{d}$ & 6.2 & 4.8 & 6.2 & 4.9 \\
\hline Heart disease & 6.2 & 5.9 & 7.4 & 7.2 \\
\hline Diabetes & 3.5 & 3.3 & 4.5 & 4.9 \\
\hline Kidney disease & 1.5 & 1.8 & 2.2 & 1.9 \\
\hline Depression & 5.1 & 5.4 & 4.6 & 3.8 \\
\hline \multicolumn{5}{|c|}{ Disease Diagnosed in First-Degree Relative } \\
\hline Breast cancer & 9.8 & 9.3 & 8.8 & 8.5 \\
\hline Lung cancer & 5.8 & 5.9 & 8.5 & 8.1 \\
\hline Colon cancer & 10.0 & 9.1 & 7.7 & 6.2 \\
\hline Melanoma & 8.1 & 6.9 & 7.9 & 6.4 \\
\hline Skin cancerc & 9.3 & 9.2 & 12.3 & 10.6 \\
\hline Stomach cancer & 3.6 & 3.4 & 3.7 & 3.9 \\
\hline Lymphoma & 2.1 & 2.2 & 1.4 & 1.6 \\
\hline Leukemia & 3.2 & 3.4 & 3.0 & 2.4 \\
\hline Brain cancer & 2.6 & 2.5 & 2.6 & 2.5 \\
\hline Prostate cancer & 10.4 & 9.5 & 8.5 & 7.6 \\
\hline Any cancer ${ }^{d}$ & 40.0 & 36.5 & 35.9 & $30.4^{e}$ \\
\hline Heart attack & 7.7 & 8.0 & 10.2 & 11.2 \\
\hline Diabetes & 20.3 & 19.0 & 24.5 & 23.5 \\
\hline Kidney failure & 2.9 & 2.8 & 4.0 & 4.8 \\
\hline
\end{tabular}

aAge-adjusted relative frequency distributions, see Table II.

${ }^{\mathrm{b}} \mathrm{Q}$, No Q, see Table I.

cNonmelanoma skin cancer.

dExcluding skin cancer.

eSignificant difference, see Table II.

chewing tobacco, alcohol consumption, and family history of specific malignancies, were small, as were differences in known protective factors, such as vegetable and fruit consumption.

The most notable difference between nonresponders and responders was the increased age of responders. This does not pose a fundamental problem for future analyses of associations between exposures and disease risk, however, because all such analyses will be age-adjusted. Previous findings related to age and nonresponse have been mixed, with some studies reporting no relationship [Oakes et al.,
1973; Criqui et al., 1978] or a direct relationship [Sheikh and Mattingly, 1981; Clark et al., 1983; Walker et al., 1987; Bakke et al., 1990; Panser et al., 1994] between age and response rate, but other studies reporting an inverse relationship [Doll and Hill, 1964; Barton et al., 1980; Benfante et al., 1989; Macera et al., 1990; Heilbrun et al., 1991; Melton et al., 1993; Bisgard et al., 1994] between age and response rate.

The direction of the association between age and response rate will likely depend on characteristics of the study population, the purpose of the study, and study recruitment methods. Examination of various predictors of response in the Agricultural Health Study suggests that the amount of available free time may be a major determinant of whether the self-administered, take-home questionnaire was completed, and that this could explain the direct relationship between age and response rate. There was an inverse relationship between age and the extent of farming enterprises, indicating that younger farmers were likely spending more time involved in farming operations, leaving less time for filling out the take-home questionnaire. In support of this conclusion, nonresponders reported planting more acres, tending a larger number of livestock, and spending more days per year involved in personally mixing and applying pesticides than responders. These results suggest that the study population may have lower current exposure, but higher cumulative exposure, than the study base population of all farmer applicators. Nonresponders also tended to have larger families and a slightly greater likelihood of having a young child at home, indicating that family responsibilities might have reduced the time available for filling out a questionnaire. Finally, the response rate in both states was significantly higher during winter months, when less time is required for farming activities.

The most consistent findings of previous studies of response have been that responders are better educated [Barton et al., 1980; Clark et al., 1983; Benfante et al., 1989; Heilbrun et al., 1991; Melton et al., 1993] and less likely to be current cigarette smokers [Doll and Hill, 1964; Oakes et al., 1973; Seltzer et al., 1975; Criqui et al., 1978; Bakke et al., 1990; Benfante et al., 1989; Macera et al., 1990; Heilbrun et al., 1991; Bisgard et al., 1994]. Both results are confirmed by the results of the Agricultural Health Study, and additional results, not directly available from prior investigations of nonresponse, suggest that responders are generally more aware of, or more concerned about, healthrelated issues than are nonresponders. Thus, responders consumed alcohol significantly less often than nonresponders, and consumed significantly more fruits and vegetables than nonresponders. A higher prevalence of clinical alcohol problems in nonresponders has been reported previously [Wilhelmsen et al., 1976]. Responders were also somewhat more likely to report use of protective equipment when mixing or applying pesticides. Use of tobacco prod- 
ucts other than cigarettes has not been examined in prior studies of nonresponse, although a slightly slower response (i.e., the percentage of eventual responders who had responded at an interim time point was used as a surrogate for response rate) in pipe and cigar smokers was previously reported [Seltzer et al., 1975]. No association was observed among farmers between response status and cigar or pipe smoking or the use of chewing tobacco or snuff.

Responders and nonresponders differed slightly in univariate analyses with regard to cigarette smoking and alcohol consumption, which are risk factors for several types of cancer, and vegetable consumption, which is a protective factor for a number of types of cancer. Thus, there might be concern that a combination of such variables might lead to a larger difference between responders and nonresponders in an accumulation of factors associated with increased risk of cancer. Accordingly, comparisons were made of the percentage of subjects who were current smokers, drank alcohol at least one time a week, and ate vegetables less than 5 times a week. The age-adjusted percentages for this combination of factors were $5.2 \%$ in Iowa responders, $7.8 \%$ in Iowa nonresponders, $4.9 \%$ in North Carolina responders, and $7.6 \%$ in North Carolina nonresponders. Although significant in both Iowa $(p=0.011)$ and North Carolina $(p=0.003)$, the magnitude of the differences, as in the case of univariate comparisons, was not substantial.

Previous diagnoses of disease or physical problems associated with pesticide application did not appear to have motivated farmers to fill out and return the take-home questionnaire. Likewise, differences in reported family history of a variety of specific cancers and other diseases were all negligible. Responders in Iowa were more likely to have mixed and applied herbicides, and reported somewhat greater use of protective equipment when mixing and applying pesticides. The interpretation of the greater use of hand spraying devices and more frequent repair of pesticide application equipment by responders is uncertain, but may indicate a perception of greater personal pesticide exposure. Taken together, these differences might indicate an increased motivation to participate due to concern resulting from publicity generated by previous epidemiologic studies that suggested possible disease risks associated with herbicide exposure. A number of these previous studies, some of which were conducted in Iowa, reported that herbicide exposure was possibly associated with an increased risk of lymphopoietic malignancies [Hoar et al., 1986; Brown et al., 1990; Zahm et al., 1990; Cantor et al., 1992]. Therefore, if past epidemiologic studies were influencing participation in the Agricultural Health Study, evidence might be expected to come from self-reports of the conditions most strongly associated with farming in these studies, namely, lymphatic and hematopoietic cancers. In fact, no greater diagnosis of, or family history of, lymphopoietic cancers was reported by responders.
For questions on the enrollment questionnaire which required study subjects to provide information on a number of related items (e.g., which of several listed pesticides they had applied) responders tended to report slightly higher percentages than nonresponders for most items (Tables VI-X). Rather than representing fundamental exposure differences between responders and nonresponders which could affect the assessment of disease risk, these systematic differences on multiple item questions may simply indicate a tendency for responders to be more compulsive in performing tasks. Such an inference is quite speculative, but like the more careful and complete reporting on the multiple item questions from the enrollment questionnaire, the higher response rate for the take-home questionnaire could reflect a greater sense of responsibility and obligation when faced with any task. Such a personality trait may also explain why responders were significantly more likely to report personal application of glyphosate, an herbicide often used for total weed control in areas not directly involved in crop production, and why a significantly higher percentage of responders reported that they painted on their farms. Both differences may reflect a more compulsive concern of responders regarding the appearance of their property.

Although the observed differences between responders and nonresponders are, in general, relatively small in magnitude, additional investigations have been initiated within the Agricultural Health Study cohort to examine the potential for responder bias and to determine the extent to which findings can be generalized to a wider population, particularly for outcomes ascertained through the take-home questionnaire. Accordingly, three random samples, one of 1,000 enrolled male subjects and two separate samples of 1,000 female spouses of enrolled farmers, will be studied in greater detail. The male sample will be composed of men 40-69 years of age. One female sample will be composed of women 30-39 years of age and the second of women 40-69 years of age. Nonrespondents in each sample will be contacted for a telephone interview covering selected questions from the longer, take-home questionnaires. These sub-studies will evaluate the potential for bias in the assessment of reproductive history (e.g., spontaneous abortion rates or age at menopause) in women and of neurologic and immunologic diseases in men.

The enrollment questionnaire in the Agricultural Health Study was 17 pages long, and thus it was possible to evaluate the impact on response of many more variables than were examined in previous studies of response. In spite of the length of the enrollment questionnaire, the enrollment rate was higher than has been observed in other large prospective studies, and thus our investigation involved a larger percentage of the targeted population than most previous studies of response. Our study of farmers enrolled in the Agricultural Health Study found little difference between the characteristics of subjects who completed only the enrollment question- 
naire and those who also chose to complete and return the lengthy, take-home questionnaire. Although statistically significant differences between respondents and nonrespondents were observed, most were small in magnitude and would not be expected to compromise etiologic inferences based on prospectively ascertained health outcomes. Age, the attribute that varied most between responders and nonresponders, is easily taken into account in statistical analyses. The lack of evidence for substantial selection bias is reassuring for the Agricultural Health Study and, although the potential for selection bias should be evaluated in each study, may provide some reassurance for other epidemiologic studies which depend upon voluntary completion of self-administered questionnaires.

\section{REFERENCES}

Alavanja MCR, Sandler DP, McMaster SB, Zahm SH, McDonnell CJ, Lynch CF, Pennybacker M, Rothman N, Dosemeci M, Bond AE, Blair A (1996): The Agricultural Health Study. Environ Health Perspect 104:362369.

Bakke P, Gulsvik A, Lilleng P, Overa O, Hanoa R, Eide GE (1990): Postal survey on airborne occupational exposure and respiratory disorders in Norway: causes and consequences of non-response. J Epidemiol Community Health 44:316-320.

Barton J, Bain C, Hennekens CH, Rosner B, Belanger C, Roth A, Speizer FE (1980): Characteristics of respondents and non-respondents to a mailed questionnaire. Am J Public Health 70:823-825.

Benfante R, Reed D, MacLean C, Kagan A (1989): Response bias in the Honolulu heart program. Am J Epidemiol 130:1088-1100.

Bisgard KM, Folsom AR, Hong CP, Sellers TA (1994): Mortality and cancer rates in nonrespondents to a prospective study of older women: 5-year follow-up. Am J Epidemiol 139:990-1000.

Blair A (1992): An overview of potential health hazards among farmers from use of pesticides. In Myers ML, Herrick RF, Olenchock SA, Myers JR, Parker JE, Hard DL, Wilson K (eds): 'Papers and Proceedings of the Surgeon General's Conference on Agricultural Safety and Health. 'DHHS (NIOSH) Publ \#92-105. Cincinnati, OH, pp. 229-242.

Blair A, Zahm SH (1991): Cancer among farmers. In Cordes DH, Rea DF (eds): "Health Hazards of Farming." Occup Med: State of the Art Reviews 6:335-349. Philadelphia: Hanley and Belfus.

Boice JD, Mandel JS, Doody MM (1995): Breast cancer among radiologic technologists. JAMA 274:394-401.

Brown LM, Blair A, Gibson R, Everett G, Cantor KP, Schuman L, Burmeister L, Van Lier S (1990): Pesticide exposures and other agricultural risk factors for leukemia among men in Iowa and Minnesota. Cancer Res 50:6585-6591.

Cantor KP, Blair A, Everett G, Gibson R, Burmeister LF, Brown LM, Schuman L, Dick FR (1992): Pesticides and other agricultural risk factors for non-Hodgkin's lymphoma among men in Iowa and Minnesota. Cancer Res 52:2447-2455.

Chow WH, Schuman LM, McLaughlin JK, Bjelke E, Gridley G, Wacholder S, Co Chien HT, Blot WJ (1992): A cohort study of tobacco use, diet, occupation, and lung cancer mortality. Cancer Causes Control 3:247-254.

Clark VA, Aneshensel CS, Frerichs RR, Morgan TM (1982): Analysis of non-response in a prospective study of depression in Los Angeles County. Int J Epidemiol 12:193-198.
Criqui MH, Barrett-Connor E, Austin M (1978): Differences between respondents and non-respondents in a population-based cardiovascular disease study. Am J Epidemiol 108:367-372.

Doll R, Hill AB (1964): Mortality in relation to smoking: ten years' observations of British doctors. Br Med J 1:1399-1410.

Edgerton HA, Britt SH, Normal RD (1943): Objective differences among various types of respondents to a mailed questionnaire. Am Sociol Rev 8:433-438.

Heilbrun LK, Nomura A, Stemmermann GN (1991): The effects of non-response in a prospective study of cancer: 15-year follow-up. Int J Epidemiol 20:328-338.

Hoar SK, Blair A, Holmes FF, Boysen CD, Robel RJ, Hoover R, Fraumeni JF JR (1986): Agricultural herbicide use and risk of lymphoma and soft-tissue sarcoma. JAMA 256:1141-1147

Macera CA, Jackson KL, Davis DR, Kronenfeld JJ, Blair SN (1990): Patterns of non-response to a mail survey. J Clin Epidemiol 43:1427-1430.

Melton LJ, Dyck PJ, Karnes JL, O’Brien PC, Service FJ (1993): Nonresponse bias in studies of diabetic complications: The Rochester Diabetic Neuropathy Study. J Clin Epidemiol 46:341-348.

Miller RG (1981): "Simultaneous Statistical Inference." New York: Springer-Verlag.

Oakes TW, Friedman GD, Seltzer CC (1973): Mail survey response by health status of smokers, nonsmokers, and ex-smokers. Am J Epidemiol 98:50-55.

Panser LA, Chute CG, Guess HA, Larsonkeller JJ, Girman CJ, Oesterling JE, Lieber MM, Jacobsen SJ (1994): The natural history of prostatism: The effects of non-response bias. Int J Epidemiol 23:1198-1205.

Potter JD, Sellers TA, Folsom AR, McGovern PG (1992): Alcohol, beer and lung cancer in postmenopausal women: The Iowa Women's Health Study. Ann Epidemiol 2:587-595.

Seltzer CC, Bosse R, Garvey AJ (1975): Mail survey response by smoking status. Am J Epidemiol 100:453-417.

Sheikh K, Mattingly S (1981): Investigating non-response bias in mail surveys. J Epidemiol Community Health 35:293-296.

Suchman EA, McCandless B (1940): Who answers questionnaires? J Appl Psychol 24:758-769.

Thomas DG, Gart JJ (1983): Stratified trend and homogeneity analysis of proportions and life table data. Comp Biomed Res 16:116-126.

Wacholder S, McLaughlin JK, Silverman DT, Mandel JS (1992): Selection of controls in case-control studies. I. Principles. Am J Epidemiol 135:10191028 .

Wallace D (1947): Mail questionnaires can produce good samples of homogeneous groups. J Marketing 12:53-60.

Walker M, Shaper AG, Cook DG (1987): Non-participation and mortality in a prospective study of cardiovascular disease. J Epidemiol Community Health 41:295-299.

Wilhelmsen L, Ljungberg S, Wedel H, Werko L (1976): A comparison between participants and non-participants in a primary preventive trial. J Chron Dis 29:331-339.

Zahm SH, Weisenberger DD, Babbitt PA, Saal RC, Vaught JB, Cantor KP, Blair A (1990): A case-control study of non-Hodgkin's lymphoma and the herbicide 2,4-dichlorophenoxyacetic acid (2,4-D) in eastern Nebraska. Epidemiology 1:349-356. 